\title{
Surface suspended matter off the Rhone river mouth from visible satellite imagery
}

\author{
Philippe FORGET, Sylvain OULLLON
}

Laboratoire de sondages électromagnétiques de l'environnement terrestre, UPRESA 6017 CNRS, université de Toulon et du Var, BP 132, 83957 La Garde cedex. France

(Revised 17 March 1998, accepted 24 March 1998)

\begin{abstract}
The quantification of surface Total Suspended Matter (TSM) off the Rhone river mouth is investigated using SPOT-XS and Landsat-TM images collected in November 1994. The method of satellite data calibration from in situ measurements is discussed. It is based on TSM concentration measurements through filtration of surface water samples and on radiometric data collected with a 256-channel spectroradiometer in the range $400-1100 \mathrm{~nm}$. Empirical relationships between reflectance and TSM concentration are established by linear regression analysis of the data. These relationships are then applied to the image data corrected from atmospheric and surface effects. A good agreement, within a factor of less than two, was found on derived TSM concentration values as compared with sea truth data. The results for three different river flows are presented: a quasi-normal river discharge, a flood situation and an intermediate situation. The TSM corresponding concentration maps are presented and discussed. Elsevier, Paris
\end{abstract}

reflectance / suspended matter / remote sensing / river plume / Rhone river

Résumé - La matière en suspension au large de l'embouchure du Rhône, mesurée par imagerie satellitale dans le visible. Des images SPOT-XS et Landsat-TM acquises en novembre 1994 sont utilisées pour quantifier la Matière en Suspension Totale (TSM) en surface, devant l'embouchure du Rhône. Nous présentons la méthode de calibration des données satellitales à partir de mesures in situ. Cette méthode est basée sur des mesures de concentration de TSM par filtration d'échantillons d'eau, et sur des mesures radiométriques simultanées, réalisées à l'aide d'un spectroradiomètre à 256 canaux de 400 à $1100 \mathrm{~nm}$. Des relations empiriques entre réflectance et concentration sont établies par régression linéaire des données. Ces relations sont ensuite appliquées aux données d'images satellitales corrigées des effets atmosphériques et de surface. Les concentrations obtenues par inversion des images concordent assez bien avec les concentrations d'échantillons prélevés en mer, à des fins spécifiques de validation (différences d'un facteur inférieur à 2). Nous présentons les résultats correspondant à trois différents débits du fleuve : un débit quasi-normal, une situation de crue et une situation intermédiaire. Les cartes de concentration de TSM correspondant à ces situations sont présentées et discutées. @ Elsevier, Paris

réflectance / matière en suspension / télédétection / panache fluvial / Rhône

\section{INTRODUCTION}

From a biogeochemical point of view, coastal zones are sensitive areas of great variability. They continuously receive sediment supplies, especially from rivers, which evolve under the combined influences of wind and sea dynamics. Both field measurements and numerical mod- elling are necessary to quantify biogeochemical fluxes and to describe the associated dynamics. Field surveys are expensive and give limited access to the synoptic description of the phenomena. On the other hand, one difficulty in numerical modelling is to acquire accurate data for calibrating and for validating the model over specitic sites. 
Satellite remote sensing can be a valuable means for getting the spatial distribution of sediment in the water surface layer to test sediment transport models $[3,19]$ and, in conjunction with hydrodynamical modelling, to quantify sediment fluxes and deposit rales. Sediment is part of the Total Suspended Matter (TSM) in seawater. TSM includes a great variety of particles of physical and biological origins [16], and difficulties still remain in the use of remote sensing data for discriminating the nature and the respective amounts of its different components $[5$, 11]. This study is restricted to the measurement of surface TSM concentration from visible satellite imagery, and specifically from Landsat and SPOT imageries. This problem is well documented concerning Landsat-TM [6, $22,27]$ contrary to SPOT, for which few references are available on the subject $[7,13]$. AVHRR also has been used in studies of the distribution of suspended sediment in coastal areas $[8,25]$.

An experiment was carried out in 1994 in the region of the Rhone river mouth (south of France) to study the plume dynamics and related biogeochemical phenomena. This paper deals with the use of satellite remote sensing data, consisting of two SPOT-XS images and one Landsat-TM image, for mapping surface TSM concentrations. First we describe environmental and experimental conditions. Then we discuss the method used to calibrate the satellite images from water sampling data and from radiometric measurements. Finally the results are presented and discussed.

\section{ENVIRONMENTAL AND EXPERIMENTAL CONDITIONS}

The overall experiment consisted of the monitoring of surface currents by VHF radar, hydrological measurements and using satellite imagery for investigating the river plume dynamics and biochemical features. A detailed description of the experiment can be found in Broche et al. [2]. Hydrological measurements consisted of conductivity-temperature-depth (CTD) soundings and water samplings. They were performed from the French Oceanographic Research Vessel Professeur Georges-Petit during two cruises, at the beginning and at the end of November.

Figure 1 shows the site of the Rhone river mouth and its bathymetry. The river Rhone provides $5 \times 10^{6} 1010^{7} \mathrm{t}^{-1}$ of minerals into the Mediterranean Sea in France. The mean flow of the river is about $1700 \mathrm{~m}^{3} \mathrm{~s}^{-1}$. The plume,

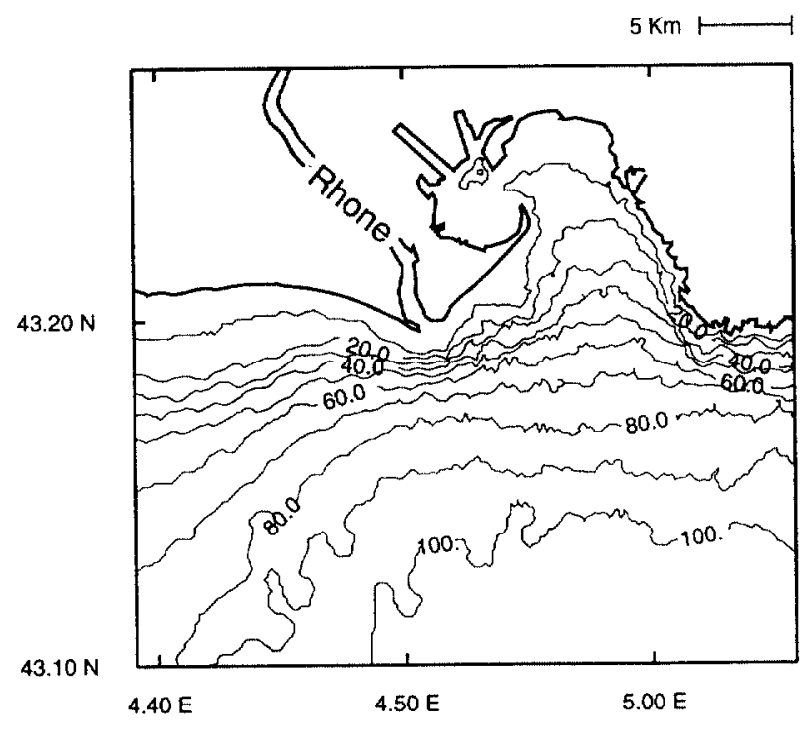

Figure 1. The site of the study. Iso-depth contours are labelled in metres.

generally one to three meters thick in the vicinity of the mouth, is mainly influenced by the river discharge, the wind, the sea state and the Liguro-Provençal current coming from the east [15]. The dominant wind blows from the north and is known as "Mistral". The experiment took place in November 1994. A 50-year flood occurred at the beginning of the month, with a maximum flow at the river mouth estimated to $9000 \mathrm{~m}^{3} \mathrm{~s}^{-1}$ on 7 November. Then the flow decreased more or less continuously to $1800 \mathrm{~m}^{3} \mathrm{~s}^{-1}$ on 26 November, with a slight rise on 11 November $\left(4000 \mathrm{~m}^{3} \mathrm{~s}^{-1}\right)$.

For TSM concentration mapping by satellite imagery, we used two multispectral (XS) HRV/SPOT-3 images and one TM/Landsat-5 image acquired on 10 November at $10 \mathrm{~h} 54$ UT (HRV2 sensor), 26 November at $10 \mathrm{~h} 46 \mathrm{UT}$ (HRV1 sensor) and 15 November at 09 h 38 UT, respectively. Water samples were collected simultaneously with radiometric measurements on 4 and 5 November. A series of water samples wcre collected on 26 November during the SPOT overpass to be used as sea-truth data.

\section{RADIOMETRIC MEASUREMENTS AND DATA} ANALYSIS

\subsection{Radiometric measurements}

Radiometric measurements were performed at the sea surface on 4 and 5 November using a Spectron SE-590 
spectroradiometer fitted with 256 sensors in the range $400-1100 \mathrm{~nm}$ (dispersion: $2.8 \mathrm{~nm}$ per element; full-width half-peak: $10 \mathrm{~nm}$ ). Each measurement consisted of the downwelling irradiance spectrum $\left(E_{d}^{+}(\lambda)\right)$ above the sea surface and the upwelling radiance spectrum $\left(L_{u t}^{+}(\lambda)\right)$ converted into the upwelling irradiance spectrum $\left(E_{u}^{+}(\lambda)\right)$ using: $E_{u}^{+}(\lambda)=\pi L_{u}^{+}(\lambda)$. These spectra resulted from the averaging of three to four spectra acquired within less than two minutes.

By definition, the measured reflectance $\left(R^{+}(\lambda)\right)$ above sea surface is given by:

$R^{+}(\lambda)=\frac{E_{u}^{+}(\lambda)}{E_{d}^{+}(\lambda)}$

The upwelling irradiance is the sum of two terms: the irradiance of sun light reflected by the water surface and the irradiance of light coming from the water through the interface. The contribution of these terms to $R^{+}(\lambda)$ are the reflectivity $(\rho(\lambda))$ and the water reflectance above sea surface $\left(R_{w}^{+}(\lambda)\right)$ following:

$R^{+}(\lambda)=R_{n}^{+}(\lambda)+\rho$

The reflectivity depends mainly on the sea surface roughness and is assumed to be independent of wavelength from the visible to the near-IR [17]. The subsurface reflectance $R(\lambda) \equiv R^{-}(\lambda)$, which is a fundamental radiometric quantity used in ocean optics [16] can be derived from $R_{w}^{+}(\lambda)$ by [17]:

$R(\lambda)=\frac{R_{w}^{+}(\lambda)}{0.54}$

We assume that $\rho$ was constant during each measurement sequence (two hours on 4 November, one hour on 5 November) and that $R_{w}^{+}$was negligible in near-IR for the clearest waters. According to these assumptions, $\rho$ is equal to the mean value of $R^{+}$between 970 and $1010 \mathrm{~nm}$ for the data relative to the clearest waters encountered during each experiment. This represents between $3.1 \%$ (4 November) and $3.6 \%$ ( 5 November) of the observations.

Simultaneously to optical measurements, the TSM concentrations were determined on water samples collected at a depth of about $30 \mathrm{~cm}$. Filters of porosity $0.47 \mu \mathrm{m}$ were used to separate dissolved and suspended matcrials.
Figure 2 shows the reflectance spectra $R(\lambda)$ obtained for a range of TSM concentrations with values between 3.7 and $234 \mathrm{mg} \mathrm{L}^{-1}$. The general aspect of these spectra and their variations with concentration are found similar to other experimental results, e.g. to those obtained by Ritchie et al. [21].

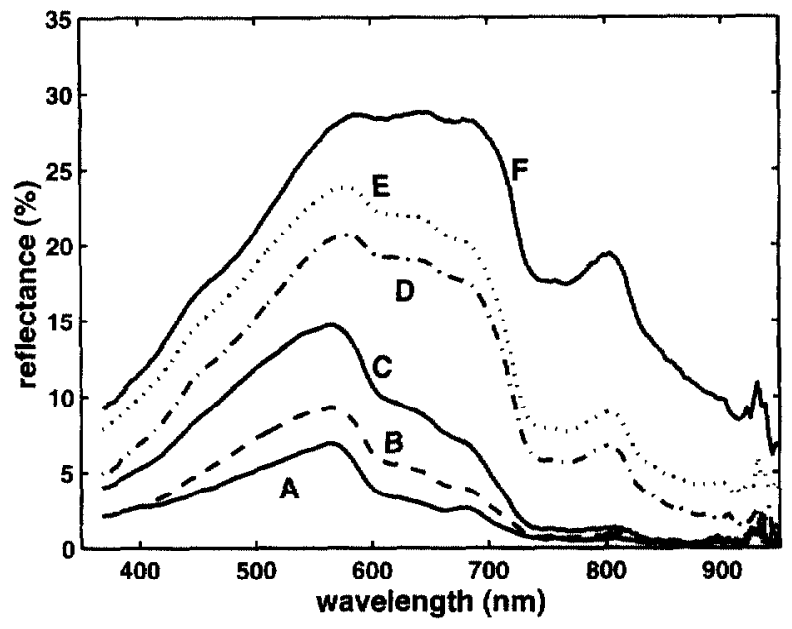

Figure 2. Reflectance spectra obtained from spectroradiometric measurements of 4 and 5 November. The corresponding values of concentration of the surface total suspended matter are: $3.9 \mathrm{mg} \mathrm{L}^{-1}$ (A), $3.7 \mathrm{mg} \mathrm{L}^{-1}$ (B), $19.1 \mathrm{mg} \mathrm{L}^{-1}$ (C), $55.7 \mathrm{mg} \mathrm{L}^{-1}$ (D), $56.4 \mathrm{mg} \mathrm{L}^{-1}$ (E), $234 \mathrm{mg} \mathrm{L}^{-1}$ (F).

\subsection{Relationship between satellite equivalent reflec- tance and TSM concentration}

The satellite equivalent reflectances above sea surface for $\mathrm{XS}$ and TM visible channels are computed from:

$R_{k}^{+}=\frac{\int_{0}^{\infty} E_{u}^{+}(\lambda) S_{k}(\lambda) d \lambda}{\int_{0}^{\infty} E_{d}^{+}(\lambda) S_{k}(\lambda) d \lambda}$

where $S_{k}(\lambda)$ is the spectral response function of channel $k$ [1]. Here, $k$ is equal to XS1 or XS2 for XS channels and TM1, TM2 or TM3 for TM channels. The integrals in (4) are calculated using appropriate discretized forms. The satellite equivalent reflectances below the sea surface $\left(R_{k}\right)$ were derived following eq. 2 and eq. 3 using the values of reflectivity previously obtained from continuous spectra.

A linear regression analysis was applied to $R_{k}$ and TSM concentration values. This analysis gave the best correla- 
tion using a $\log$-linear relationship ( $R$ versus $\log _{10}(T S M)$ ). The regression and correlation coefficients are listed in table $I$ and figure 3 reports the experimental data and the regression lines. For SPOT data, a log-linear relationship between suspended sediment concentration and reflectance was also found by Lathrop and Lillesand [13].
There exists a variety of relationships for Landsat-TM data: linear-linear [22], log-linear [18], log-log [26], polynomial relationship [6]. It can be seen on our data that the channel sensitivity to TSM concentration variations increases with wavelength from blue to red, which is in agreement with all previous studies [11]. In fact,
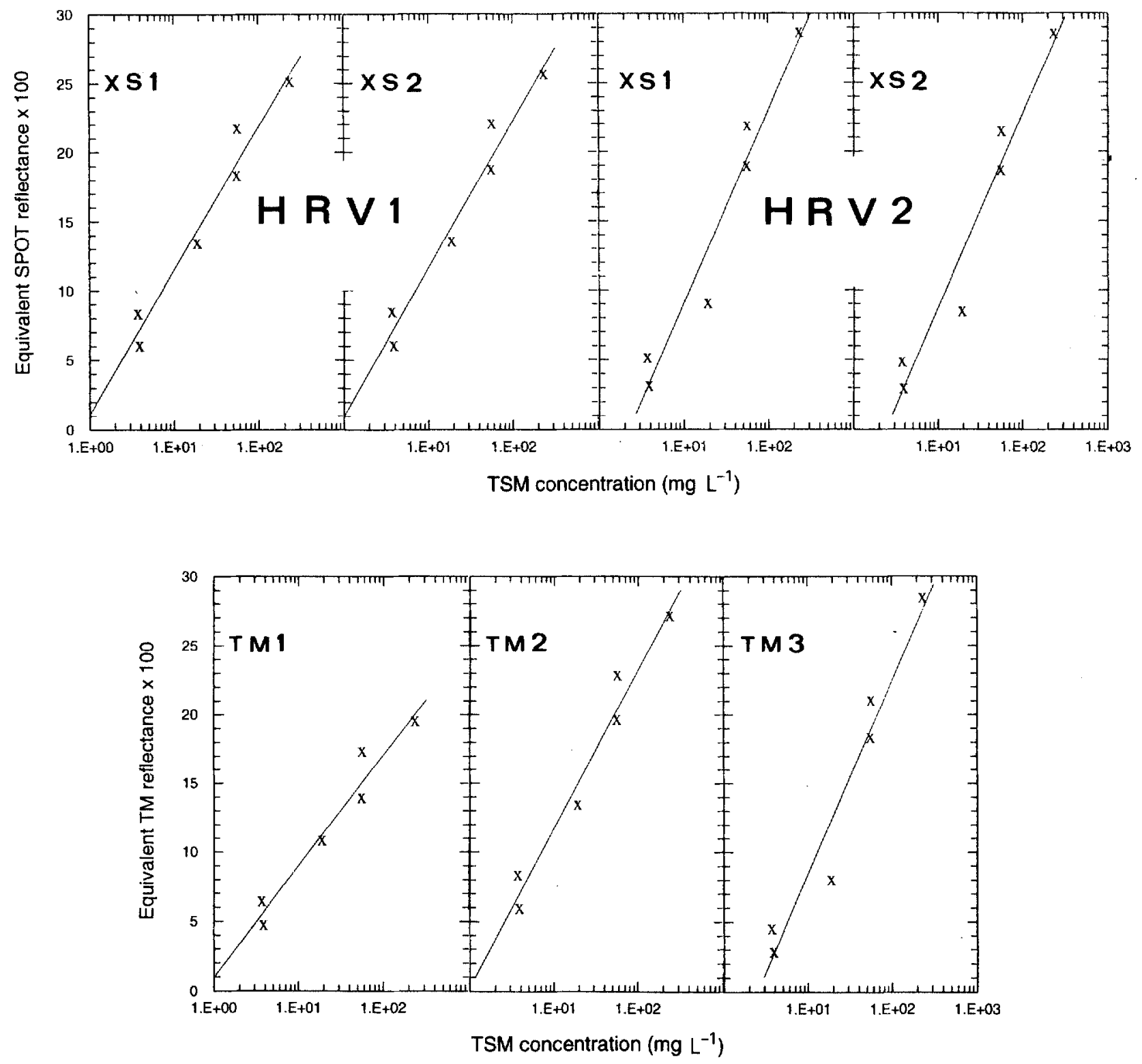

Figure 3. Channel-integrated subsurface reflectances as derived from spectra of figure 2 versus surface TSM concentration. Regression lines are drawn. XS1, XS2 designate the channels of the HRV1 and HRV2 instruments of SPOT and TM1, TM2, TM3 designate the channels of the Thematic Mapper of LANDSAT. The spectral bands of these channels are: 500-590 nm (XS1), 610-680 nm (XS2), 450-520 nm (TM1), $520-600 \mathrm{~nm}$ (TM2), 630-690 nm (TM3) 
Table I. Coefticients of the relationship: $R_{k}=a_{k} \log _{\ell !} T S M+b_{k}$ between reflectance $R_{k}$ (in percent) and TSM concentration (mg $\mathrm{L}^{-1}$ ) as determined by regression analysis and correlation coefficient $r$.

\begin{tabular}{lcrrr}
\hline Sensor & Channel & $\mathbf{a}_{\mathbf{k}}$ & $\mathbf{b}_{\mathbf{k}}$ & $\mathbf{r}$ \\
\hline HRV1 & XS1 & 10.365 & 1.122 & 0.980 \\
HRV1 & XS2 & 13.929 & -4.859 & 0.975 \\
HRV2 & XS1 & 10.623 & 0.999 & 0.981 \\
HRV2 & XS2 & 13.973 & -5.237 & 0.973 \\
TM & TM1 & 8.059 & 0.947 & 0.975 \\
TM & TM2 & 11.514 & 0.249 & 0.982 \\
TM & TM3 & 13.977 & -5.509 & 0.972 \\
\hline
\end{tabular}

TM1, the blue channel of Landsat-TM, is rarely used for measurements of suspended matter in water and it will not be considered hereafter.

\section{SATELLITE DATA PROCESSING}

The XS data were corrected from radiometric effects by SPOT Image Corporation (level $1 \mathrm{~B}$ images) and the TM data were corrected from radiometric and geometric effects by Eurimage Scrl. For each scene, the processing consists of converting the multi-band image into an image of the TSM concentration field. This is done in five steps: conversion of image pixel intensities into extraatmospheric radiances $L_{k}^{*}$ by applying given absolute gain coefficients; atmospheric corrections to get the channelintegrated reflectances $R_{k}^{1}$ above sea surface; surface effects corrections to get the channel-integrated reflectances $R_{k}$ below sea surface; conversion of $R_{k}$ values into TSM concentration values; combination of the channels to derive the final TSM concentration map.

\subsection{Atmospheric and surface effects corrections}

The extra-atmospheric radiance $L_{k}^{*}$ measured by the satellite sensor in channel $k$ is related to the water leaving radiance (propagating towards the sensor) $L_{k}^{+}$by:

$L_{\mathrm{k}}^{*}=L_{a, k}+L_{R, k}+L_{\mathrm{k}}^{+} T_{d, k}$

where $L_{a, k}$ and $L_{R, k}$ are the radiances integrated over channel $k$ of light scaltered from aerosols (Mie scattering) and from molecules (Rayleigh scattering) respectively, and $T_{d, k}$ is the diffuse transmittance coefficient of the atmosphere in channel $k$. The reflectance $R_{k}^{+}$above sea surface is related to $L_{k}^{+}$by:
$R_{k}^{+}=\frac{\pi L_{k}^{+}}{E_{d, k}^{+}}$

Atmospheric corrections were performed on $L_{k}^{*}$ values using the 6S (Second Simulation of the Satellite Signal in the Solar Spectrum) computer code developed at University of Lille [28]. $6 \mathrm{~S}$ calculates the satellite reflectance $R_{k}^{+}$above sea surface from the extra-atmospheric radiance $L_{k}^{*}$ taking into account the sun angle, the satellite view angles, the gaseous composition of a standard atmosphere specified by latitude and season, the relative contents in aerosols, the air visibility and the channel sensitivity.

As for the processing of field radiometric data, we assume that water reflectance $R_{n, k}^{+}$was equal to zero in near-IR for the clearest waters in each image. The reflectivity $\rho$ is then given by the value of $R_{\text {XS3 }}^{+}$(XS data) or $R_{\text {TM4 }}^{+}$(TM data) calculated by $6 \mathrm{~S}$ from $L_{\mathrm{XS} 3}^{+}$or $L_{\mathrm{TM} 4}^{+}$over the marine areas of the image where the digital counts are minimal. Finally, equations similar to eqs. 2 and 3 are applied to $R_{k}^{+}$values to obtain maps of subsurface reflectances $R_{k}$.

\subsection{Deriving Total Suspended Matter maps}

In clear and shallow water, the signal measured above the sea surface can be strongly dependent on sea bed reflectivity [23]. Considering a penetration depth in the visible to be $10 \mathrm{~m}$ (moderately turbid waters as here outside the plume), it can be seen on figure / that the corresponding iso-depth contour is at a distance of less than $4 \mathrm{~km}$ from the coastline in our region of interest. Close to the river mouth, where the water turbidity is maximum (a few $\mathrm{mg} \mathrm{L}^{-1}$ ), the distance is typically of $2 \mathrm{~km}$. Thus we can expect some contribution of the sea bed to the water leaving radiance only close to the coast. Elsewhere, at great 
depths as well as in the vicinity of the river mouth, this contribution is negligible.

Figure 4 compares the TSM concentration estimates obtained for each channel from our empirical relationships $R_{k}$ versus TSM concentration (table $I$ ). For SPOT data, XS2 estimates are in average higher than XS1s by a factor less than 2 for TSM concentrations lower than $5 \mathrm{mg} \mathrm{L}^{-1}$ and greater than $15 \mathrm{mg} \mathrm{L}^{-1}$, except within an interval centred on $10 \mathrm{mg} \mathrm{\textrm {L } ^ { - 1 }}$ for which they can be smaller. These differences can be attributed to the uncer- tainty of the atmospheric parameters considered for the atmospheric corrections (aerosol contents, visibility) and by the limited experimental data available for establishing the inversion relationships, in particular for TSM values smaller than $10 \mathrm{mg} \mathrm{L}^{-1}$. The choice of a log-linear relationship between concentration and reflectance fits XS1 data but leads to a poorer agreement for XS2 data. Nevertheless, we observed no significant difference between the TSM maps obtained from the two channels. The same observations hold for Landsat TM2 and TM3
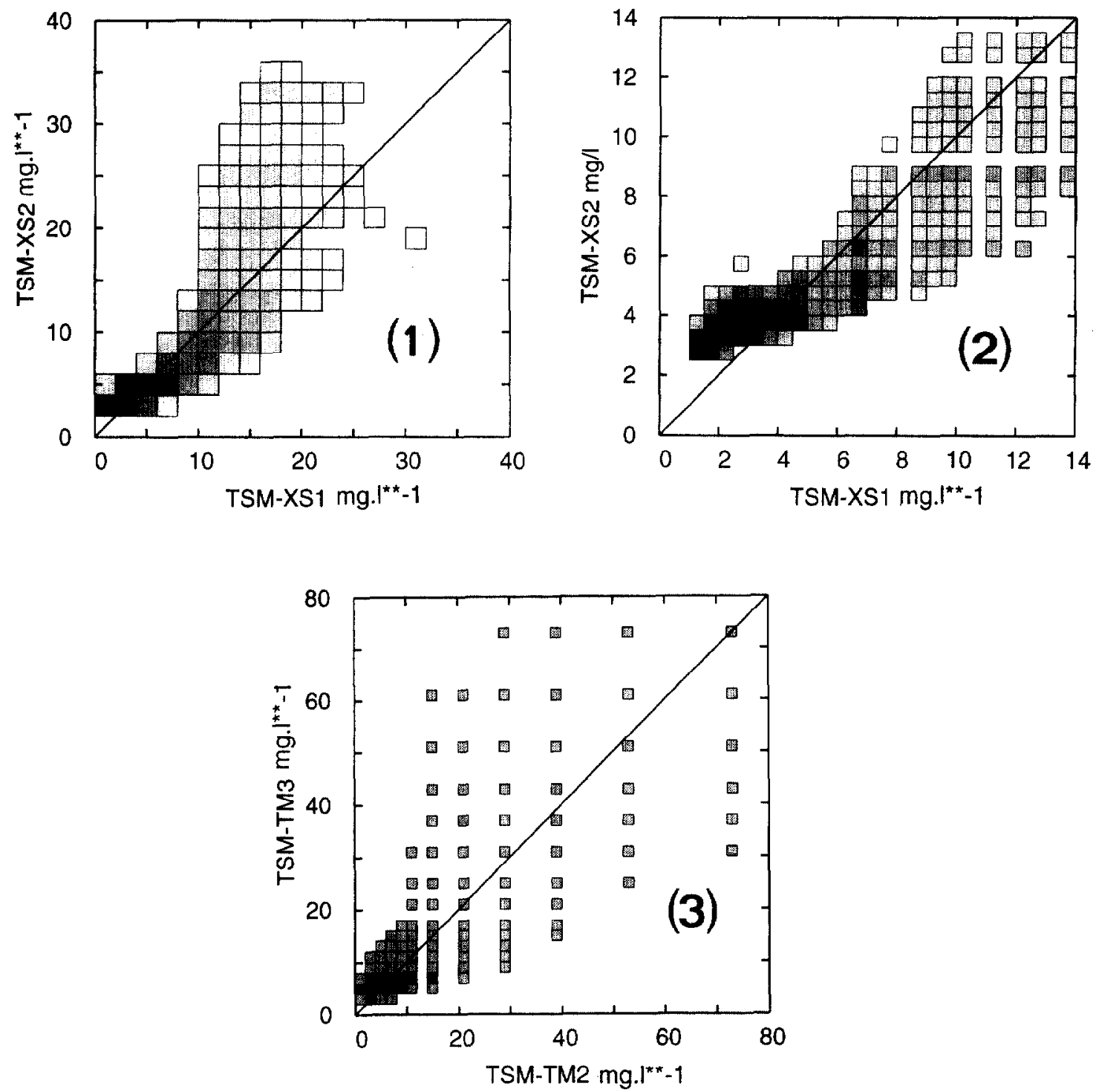

Figure 4. Comparison of surface TSM concentrations derived from the reflectance values obtained in different channels. (1) 10 November, SPOT-XS; (2) 26 November, SPOT-XS; (3) 15 November, Landsat TM. The number of points falling in a given mesh of the concentration grid is represented on a grey scale. White: no data; black: $16.7 \%$ of the total number of points (1), 10.4\% (2), $15.6 \%(3)$. 
data. Moreover, the experimental points present a larger scatter for TM than for SPOT data, which can be explained by the poorer quality of the TM data due to lineage.

The concentrations obtained from channels XS1 and XS2 (TM2 and TM3 resp.) were averaged to produce the final concentration maps. Portions of these maps are shown on figure 5 .

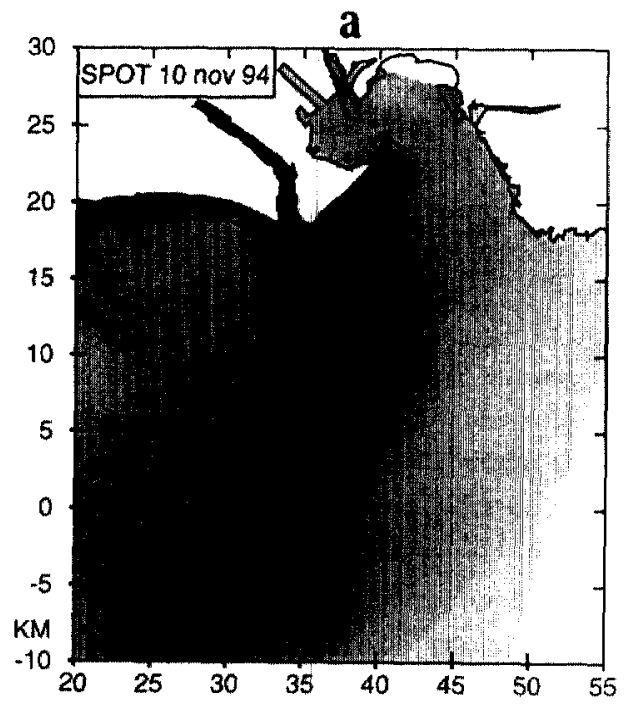

Four water samples were collected at sea within an interval of two hours during the SPOT overpass of 26 November (unfortunately, no field measurements were available for the two other satellite overpasses). The TSM concentration values were $8.5,9.8$ and $9.2 \mathrm{mg} \mathrm{L}^{-1}$ inside the plume and $1.8 \mathrm{mg} \mathrm{L}^{-1}$ outside. The satellite derived values at the same locations are 5.0, 5.6, 5.1 and $1.5 \mathrm{mg} \mathrm{L}^{-1}$, respectively. The comparison is quite satisfactory for low

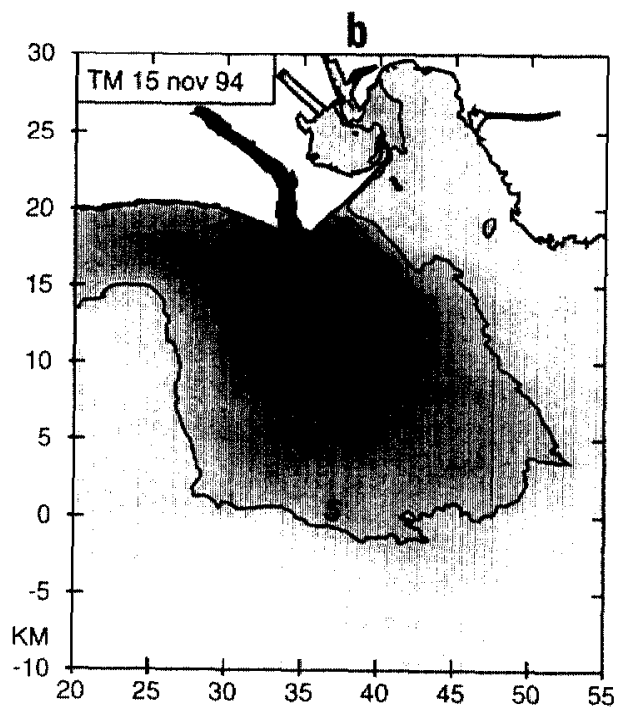

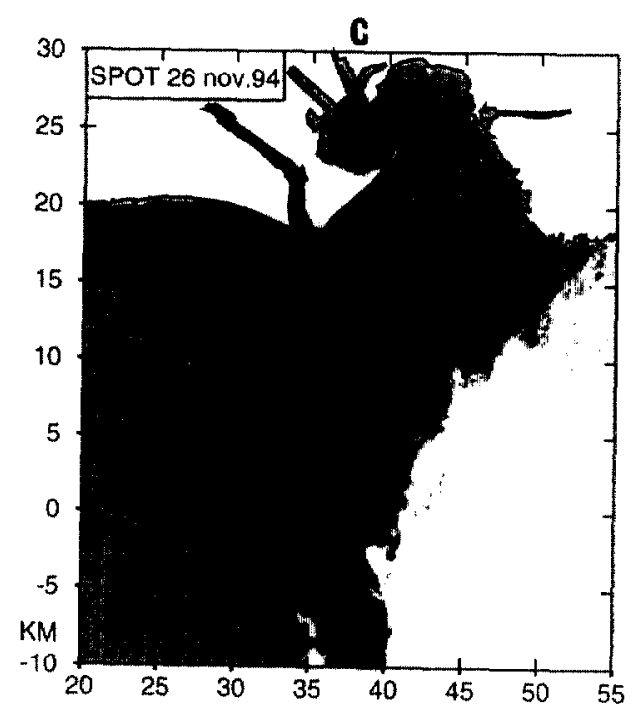

Figure 5. Surface TSM concentration maps derived from SPOT-XS and Landsat-TM images. (a) 10 November, TSM $\max =30$ mg L $\mathrm{L}^{-1}$; (b) 15 November, $T S M_{\max }=72 \mathrm{mg} \mathrm{L}^{-1}$ (c) 26 November, $T S M_{\text {max }}=6 \mathrm{mg} \mathrm{L}^{-1}$. Iso-concentration lines are labelled in $\mathrm{mg} \mathrm{L}^{-1}$. 
concentrations whereas higher values are slightly underestimated by the inversion procedure.

\section{DISCUSSION OF THE RESULTS}

\subsection{SPOT image of 10 November}

A $7.0 \mathrm{~m} \mathrm{~s}^{-1}$ wind had been blowing for two hours from WNW. The day before, the wind was from the SE with a slightly higher velocity $\left(10 \mathrm{~m} \mathrm{~s}^{-1}\right.$ in the evening), then it vecred gradually and blew successively from the south and from the west during the night. The Rhone discharge was nearly $3400 \mathrm{~m}^{3} \mathrm{~s}^{-1}$ at the time of the satellite overpass. The flow had been decreasing since the flood event of 7 November, and carrying waters of high turbidity into the sea (figure $5 a$ ). Surface currents up to $1.2 \mathrm{~m} \mathrm{~s}^{-1}$ were measured by radar $1 \mathrm{~km}$ off the mouth of the Rhone.

The turbid plume is well identified near the river mouth. The boundaries of the plume are characterised by sharp gradients of TSM concentration which nearly coincide in position to the current gradients that are detected on the corresponding surface current field measured by radar (figure $6 a$ ). The region of low TSM concentration west of the turbid plume, delimited typically by the $5 \mathrm{mg} \mathrm{L}^{-1}$ isoline (figure $5 a$ ), corresponds to the region where homogeneous wind-driven surface currents are observed. We conclude that this area is outside the actual river plume.

We observe an intensification of surface TSM loads at the boundaries of the turbid plume, in particular near the river mouth and, more clearly, on the western face of the plume. We interpret this observation as an effect of accumulation of suspended material at the plume boundaries due to dynamic processes such as frontal convergence [9]. This effect is more pronounced near the mouth where the sharpest current gradients are encountered, and especially on the western face of the plume where the wind and the associated currents act against the westward expansion of the plume and give rise to a dynamic front [2].

Turbidity patterns are observed along the coastline on both sides of the river mouth. These patterns can be accounted for by a local resuspension of sea bed material by waves (swell coming from the south sector here), by the Rhone sediment supply through coastal currents, and by the possible influence of bottom reflectivity on the satellite signal and thus on concentration estimates.

\subsection{Landsat image of 15 November}

A light wind less than $3 \mathrm{~m} \mathrm{~s}^{-1}$ was blowing from NNW after a calm episode of three hours during the previous night. A low northerly wind had been blowing the day before. The river discharge was estimated at $2300 \mathrm{~m}^{3} \mathrm{~s}^{-1}$ at the time of the satellite overpass. The flow has been decreasing since the secondary flood event of 11 November. The river brings waters of high turbidity into the sea as can be seen on figure $5 b$. Surface currents up to $1.3 \mathrm{~m} \mathrm{~s}^{-1}$ were measured by radar $1 \mathrm{~km}$ off the mouth.

The TSM concentration map differs markedly from the map of 10 November. In the vicinity of the mouth, isolines of concentration are nearly circular; concentration decreases more rapidly with increasing distance from the mouth than in the previous case; no sharp gradients can be noticed, except very close to the river mouth; the turbid plume is elongated westwards along the shoreline. The current field morphology is similar to the turbid plume morphology, except on the eastern part where sharp current gradients can be observed (figure $6 b$ ) whereas TSM concentration values vary gradually.

These features are mainly attributed to the wind influence. Contrary to 10 November, wind is low and the buoyant plume can spread freely over the seawater near the mouth which explains the circular patterns near the mouth both on TSM concentrations and on the current field.

The rapid decrease of TSM concentrations accompanied by the decrease of velocity in the first five kilometers from the mouth manifests an efficiency of particles settlement which is not observed on the 10 November map. Particle settlement is much influenced by turbulence in the water column [20]. We suggest that the weakness of the wind-induced turbulence in the surface layer is mainly responsible for the settlement efficiency of the biggest particles in conditions of low winds.

Off the mouth, both buoyancy and inertial forces act to turn the plume anticyclonically and can form a coastal current flowing parallel to the shore. Such coastal currents are expected by theory [10] and have already been observed [14]. Our turbidity and current observations support the presence of such a coastal current.

\subsection{SPOT image of 26 November}

A $8.5 \mathrm{~m} \mathrm{~s}^{-1}$ NNE wind was blowing. Wind strength and direction had been practically constant for 36 hours. The river discharge was estimated at $1800 \mathrm{II}^{3} \mathrm{~s}^{-1}$ at the time 

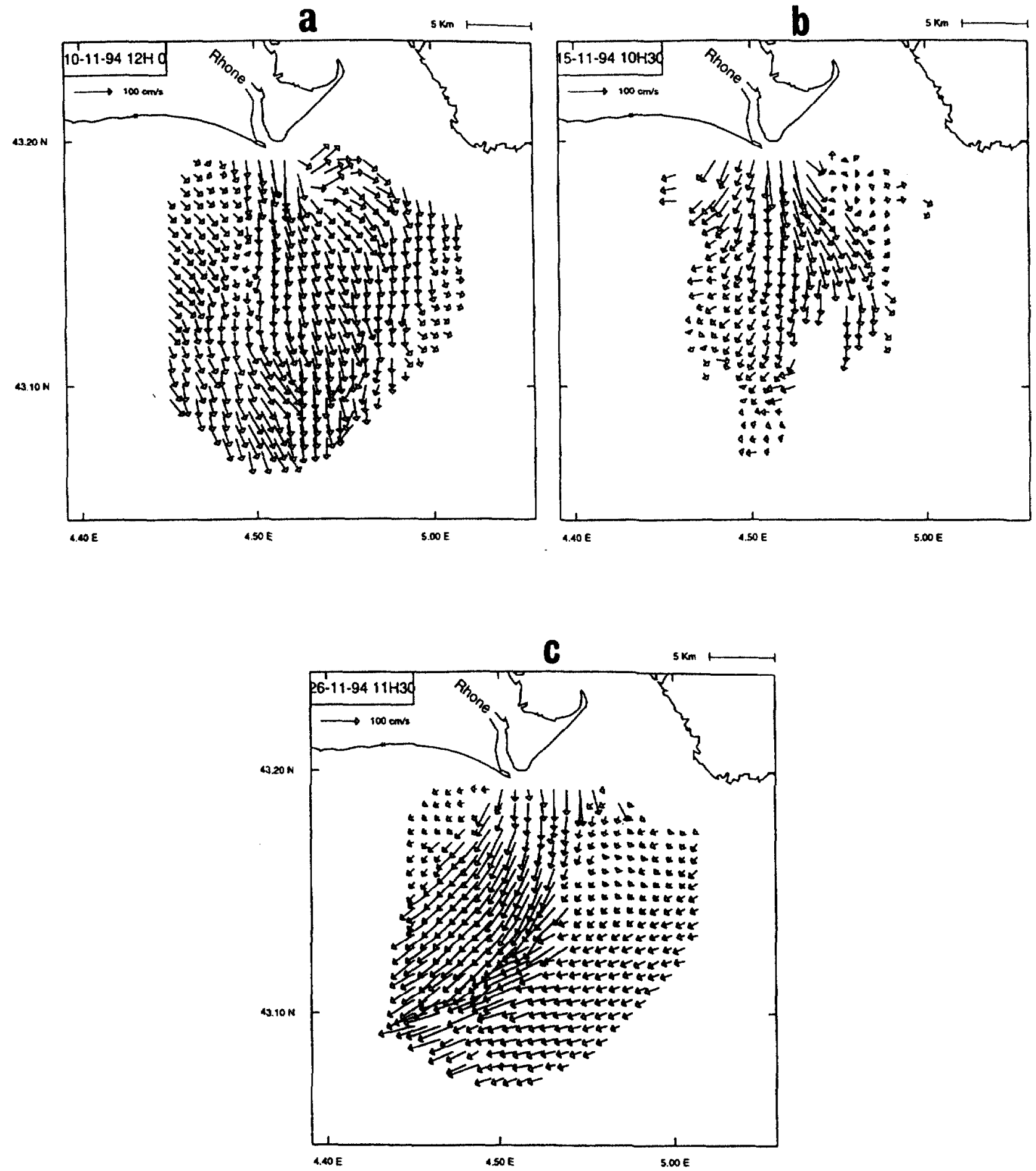

Figure 6. Surface currents mapped by VHF radar. (a) 10 November at $12 \mathrm{~h} 00$ local time ( $11 \mathrm{~h} 00$ UT); (b) 15 November at $10 \mathrm{~h} 30$ local time $(9 \mathrm{~h} 30 \mathrm{UT})$; (c) 26 November at $11 \mathrm{~h} 30$ local time (10 h $30 \mathrm{UT}$ ). Corresponding wind speed and direction: (a) $6.5 \mathrm{~m} \mathrm{~s}^{-1}$, WNW; (b) $2.8 \mathrm{~m} \mathrm{~s}^{-1}$ NNW; (c) $8.5 \mathrm{~m} \mathrm{~s}^{-1} \mathrm{NNE}$. 
of the satellite overpass. The flow had been constant for several days. The river brings waters of low turbidity into the sea as can be seen on figure $5 c$ (the maximum TSM concentration value is $6 \mathrm{mg} \mathrm{L}^{-1}$ ). Surface currents less than $1 \mathrm{~m} \mathrm{~s}^{-1}$ were measured by radar $1 \mathrm{~km}$ off the mouth.

The TSM concentration field is poorly contrasted due to the low level of turbidity of the outflow and to a background of turbidity of nearly $1.5 \mathrm{mg} \mathrm{L}^{-1}$. As on 10 November, TSM loads are greater in the vicinity of the boundaries of the turbid plume. The location of these boundaries corresponds to the fronts of the dynamic plume detected by radar (figure $6 c$ ). TSM concentration decreases gradually from the mouth along the boundaries due to mixing and settlement. Another salient feature is the presence of a turbid pattem widening westwards along the coast. The hypothesis of a coastal current emanating from the Rhone plume seems implausible since there is no continuity between the plume and this structure. Rather we suspect an artifact of TSM concentration estimates due to bottom reflectivity.

\section{CONCLUSION}

$\Lambda$ methodology was developed to estimate Total Suspended Matter concentration fields from SPOT-XS and Landsat-TM images. Sea surface reference data gener ated by in situ sampling and radiometric measurements allowed us to establish empirical relationships between reflectance and TSM concentration. These relationships were used to convert two SPOT scenes and one LandsatTM scene into maps of TSM concentration. The maps show particularly interesting features related to river plume dynamics and transport processes. Although a relatively good agreement, within a factor of 2 , has been found using derived TSM values as compared with truc sea data, improvements are envisaged in future studies to increase the confidence of the results. A confidence better than a factor of 2 in TSM values is required for numerical modelling in the coastal zone (direct and inverse problems) and for the quantification of biogeochemical fluxes. This goal could be achieved by more field data on the water contents $[4,12,24]$, on their optical properties and on atmospheric parameters such as the aerosol content.

\section{Acknowledgements}

This study was supported by the French scientific program PNOC (Programme National d'Océanographie Côtière) and by the European Community Environment Research Program Climatology and Natural Hazard (MEDDELT, contrat EV5V-CT94-0465). The authors are grateful to all members of LSEET and GDR ICO and to J.-M. Froidefond of DGO (Bordeaux) who participated in the field campaign and data analysis.

\section{REFERENCES}

[1] Begni G. Selection of the optimum spectral bands for the SPOT satellite, Photogramm. Eng. and Rem. Sens. 48 (1982) 1613-1620

[2] Broche P., Devenon J.L., Forget P., De Maistre J.C., Naudin J.J., Cauwet G., Experimental study of the Rhone plume, Oceanol. Acta 21(6) (1998) 725-738.

[3] Estournel C., Kondrachof V., Marsaleix P., Vehil R., The plume of the Rhone: numerical simulations and remote sensing, Cont. Shelf Res. 17 (1997) 899-924.

[4] Ferrari G.M., Hoepffner N., Mingazzini M., Optical properties of the water in a deltaic environment: prospective tool to analyze satellite data in turbid waters, Rem. Sens. Environ. 58 (1996) 69-80.

[5] Ferrier G., A field study of the variability in the suspended sediment concentration-reflectance relationship, Int. J. Rem. Sens. 16 (1995) 2713-2720.
[6] Forster B.C., Xingwei S., Baide X., Remote sensing of sea water quality parameters using Landsat-TM, Int. J. Rem. Sens. 14 (1993) 2759-2771.

[7] Froidefond J.M., Castaing P., Mirmand M., Ruch P., Analysis of the turbid plume of the Gironde (France) based on SPOT radiometric data, Rem. Sens. Environ. 36 (1991) 149-163.

[8] Froidefond J.M., Castaing P., Jouanneau J.M., Distribution of suspended matter in a coastal upwelling area, Satellite data and in situ measurements, J. Mar. Syst. 8 (1996) 91-105.

[9] Garvine R.W., Observation of the motion field in the Connecticut river plume, J. Geophys. Res. 82 (1977) 441-454.

[10] Garvine R.W., Estuary plumes and fronts in shelf waters: a layer model, J. Phys. Oceanogr. 17 (1987) 1877-1896.

[11] Kirk J.T.O., Light and Photosynthesis in Aquatic Ecosystems, Cambridge Univ. Press, Cambridge, 1994, 2d ed., 510 p. 
[12] Lira J., Morales A., Zamora F., Study of sediment distribution in the area of the Panuco river plume by means of remote sensing. Int. J. Rem. Sens. 18 (1997) 171-182.

[13] Lathrop R.G., Lillesand T.M., Monitoring water quality and river plume transport in Green Bay, Lake Michigan with SPOT-1 imagery, Photogramm. Eng. and Rem. Sens. 55 (1989) 349-354.

[14] Masse A.K., Murthy C.R., Observations of the Niagara River thermal plume (Lake Ontario, North America), J. Geophys. Res. 95 (1990) $16097-16109$.

[15] Millot C., The Gulf of Lions' hydrodynamics, Cont. Shelf Res. 10 (1990) 885-894.

[16] Mobley C,, Light and Water, Radiative transfer in natural waters. Academic Press, New York, 1994, 592 p.

[17] Morel A., In-water and remote measurements of ocean color, Boundary-Layer Meteorol. 18 (1980) 177-201.

[18] Munday J.C., Alfoldi T.T., Landsat test of diffuse reflectance models for aquatic suspended solids, Rem. Sens. Environ. 8 (1979) 169-183.

[19] Ouillon S., Forget P., Fraunié P., Durand N., Remote sensing as a tool for suspended sediment transport modelling in coastal areas, Proc. Third International Conference on Multiphase Flow 98, Lyon, France (1998) June 8-12, 1998.

[20] Ouillon S., Le Guennec B., Modélisation du transport de matières en suspension dans les écoulements 2D verticaux à surface libre, J. Hydraulic Res. 34 (1996) 219-236.
[21] Ritchie J.C., Schiebe F.R., McHenry J.R., Remote sensing of suspended sediment in surface waters, Photogramm. Eng. Rem. Sen. 42 (1976) 1539-1545.

[22] Ritchie J.C., Cooper C., Schiebe F.R., The relationship of MSS and TM digital data with suspended sediments, chlorophyll, and temperature in Moon Lake, Mississippi, Rem. Sens. Environ. 33 (1990) 137-148.

[23] Spitzer D., Dirks R.W.J., Bottom influence on the reflectance of the sea, Int. J. Rem. Sens. 8 (1987) 279-290.

[24] Stumpf R.P., Pennock J.R., Calibration of a general optical equation for remote sensing of suspended sediments in a moderately turbid estuary, J. Geophys. Res. 94 (1989) 14,363-14,371.

[25] Stumpf R.P., Gelfenbaum G., Pennock J.R., Wind and tidal forcing of a buoyant plume, Mobile Bay, Alabama, Cont. Shelf Res. 13 (1993) 1281-1301.

[26] Tassan S., Evaluation of the potential of the Thematic Mapper for marine application, Int. J. Rem. Sens. 8 (1987) 1455-1478.

[27] Tassan S., An improved algorithm for the determination of chlorophyll and suspended sediment concentration from Thematic Mapper data in coastal waters, Int. J. Rem. Sens. 14 (1993) 1221-1229.

[28] Vermote E., Tanré D., Deuzé J.L., Herman M., Morcrette J.J., Second Simulation of the Satellite Signal in the Solar Spectrum, 6S: an overview, IEEE Trans. Geosci. Rem. Sens. 35 (1997) 675-686. 